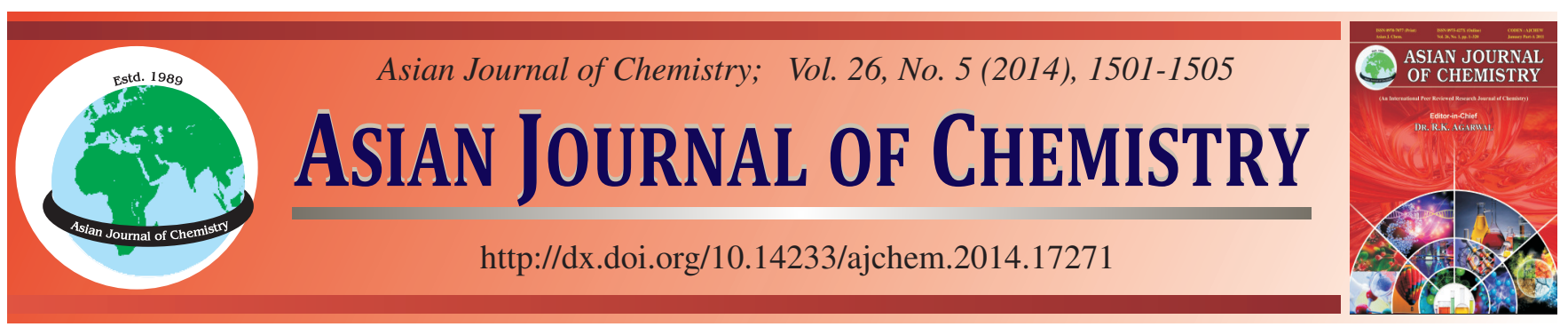

\title{
Establishing Performance of Prediction Models and Optimizing Preparation Parameters of Sintered Product Based on Response Surface Methodology $\dagger$
}

\author{
Daosheng Sun, Peng Sun, Aiguo Wang ${ }^{*}$, Wenbin Ge and Xinlan Liu
}

Anhui Key Laboratory of Advanced Building Materials, Anhui Jianzhu University, Hefei 230022, P.R. China

*Corresponding author: Fax: +86 551 3828078; E-mail: wag3134@126.com

\begin{abstract}
Sintering temperature, specific surface area of coal gangue and ratio of $\mathrm{SiO}_{2} / \mathrm{Al}_{2} \mathrm{O}_{3}$ were selected as variables and volume shrinkage ratio $(\alpha)$, apparent density $(\rho)$, vacuum water absorption $(\omega)$ and compressive strength $(\sigma)$ of sintered brick were chosen as response values. Response surface methodology (RSM) was employed to design experiment and analyze results and the quadratic regression models between properties of sintered brick and variables were established and the interaction effects of variables were also discussed, the technical parameters for the aim to prepare excellent sintered brick were optimized. The results indicated that the quadratic regression models of $\alpha, \rho$ and $\omega$ were fitted well and could be used to analyze and to predict the properties of sintered brick. Moreover, the interactions of temperature-specific surface area and temperature-Si/Al were significant for properties of sintered brick. The technical parameters for preparation of excellent sintered brick were determined by RSM, which were of $1225-1250{ }^{\circ} \mathrm{C}$ in sintering temperature, of around $600-640 \mathrm{~m}^{2} \mathrm{~kg}^{-1}$ in specific surface area of coal gangue and ratio of $\mathrm{Si} / \mathrm{Al}=2.5-2.6$.
\end{abstract}

Keywords: Sintered brick, Response surface methodology, Quadratic regression model, Properties.

\section{INTRODUCTION}

Sintered bricks are a major wall material in building sintered products for infrastructure in urban and rural areas. It has been being famous for "Qin Brick and Han Tile" in the world". Currently, more and more researchers have been focused on the preparation of sintered bricks with industrial waste. Such as, fly ash, coal gangue, sewage sludge and tailings etc., which have been widely used to produce sintered bricks ${ }^{1,2}$. Song et al. ${ }^{3}$ used coal gangue to prepare building sintered brick, it concluded that particle size of coal gangue and sintering holding time had a great influence on compressive strength and water absorption of sintered brick. Chiang et al. ${ }^{4}$ adopted sludge to prepare sintered brick and studied the effect of sintering temperature on compressive strength, volume change and water absorption. Song et al. ${ }^{5}$ reported that sintering temperature and dwell time had a significant influence on microstructure of quartz sand sintered brick. Ding et al. ${ }^{6}$ studied $\mathrm{SiO}_{2} / \mathrm{Al}_{2} \mathrm{O}_{3}$ ratio on the properties of sintered aggregate. All previous studies just investigated the influence of single factor such as sintering temperature, dwell time, particle size of raw materials and ingredients $e t c$., on the performance of sintered brick. However, the interaction effect of various factors on the performance of building sintered brick was ignored. Moreover, few reports focus on the functional relationship between the performance of sintered brick and various factors.

Response surface methodology (RSM) is the mathematical statistical method exploring the relationships between several variables and responses. Response surface methodology comprises designing experiments, building models, evaluating the effect of factors and searching for optimum parameter of factors for desirable responses ${ }^{7,8}$. In the paper, sintering temperature, specific surface area of coal gangue and $\mathrm{SiO}_{2} / \mathrm{Al}_{2} \mathrm{O}_{3}(\mathrm{Si} / \mathrm{Al})$ ratio were selected as variables and the properties (volume shrinkage ratio $(\alpha)$, apparent density $(\rho)$, vacuum water absorption $(\omega)$ and compressive strength $(\sigma)$ ) of sintered brick were chosen as response variables. DesignExpert software was used to design experiment and to analyze the experimental data. The models between variables and response values were established. Then, the interaction effects of variables on the properties of sintered brick were also discussed, as well as Design-Expert software was used to optimize the technical parameters. 
TABLE-1

CHEMICAL COMPOSITIONS OF COAL GANGUE AND FLY ASH (wt \%)

\begin{tabular}{lcccccccccc}
\hline \multicolumn{1}{c}{ Raw materials } & $\mathrm{SiO}_{2}$ & $\mathrm{Al}_{2} \mathrm{O}_{3}$ & $\mathrm{Fe}_{2} \mathrm{O}_{3}$ & $\mathrm{CaO}$ & $\mathrm{MgO}$ & $\mathrm{K}_{2} \mathrm{O}$ & $\mathrm{Na}_{2} \mathrm{O}$ & $\mathrm{SO}_{3}$ & $\mathrm{LOI}$ \\
\hline Coal gangue & 57.71 & 19.14 & 6.12 & 1.97 & 0.90 & 1.02 & 0.41 & 0.41 & 12.02 \\
Fly ash & 58.15 & 29.39 & 6.14 & 1.62 & 0.64 & 0.90 & 0.80 & 0.46 & 1.39 \\
\hline
\end{tabular}

\section{EXPERIMENTAL}

Coal gangue and fly ash were obtained from Huainan coal mine and thermal power plant in Anhui province of China, respectively. Chemical compositions of coal gangue and fly ash were shown in Table-1.

Box-Behnken design with three factors and three levels was used to fit quadratic response surface models by DesignExpert software. The factors and levels were given in Table-2. The experimental design was described in Table-3. The quadratic response surface models were built by the eqn. $1^{8}$. The fit quality of the models is evaluated by the coefficients of determination $\mathrm{R}^{2}$ and the corresponding $p$-value.

\begin{tabular}{|c|c|c|c|c|}
\hline $\begin{array}{r}\text { FACTORS AND EXPE } \\
\text { FOR RESPONSE S } \\
\end{array}$ & $\begin{array}{l}\text { LE-2 } \\
\text { IENTAI } \\
\text { ACE MI }\end{array}$ & $\begin{array}{l}\text { ESIGI } \\
\text { HODC }\end{array}$ & $\begin{array}{l}\text { EVEL } \\
\text { oGY }\end{array}$ & \\
\hline \multirow{2}{*}{ Factors } & \multirow{2}{*}{ Symbol } & \multicolumn{3}{|c|}{ Levels } \\
\hline & & -1 & 0 & 1 \\
\hline Temperature $\left({ }^{\circ} \mathrm{C}\right)$ & A & 1200 & 1250 & 1300 \\
\hline Specific surface area $\left(\mathrm{m}^{2} \mathrm{~kg}^{-1}\right)$ & B & 520 & 600 & 680 \\
\hline $\mathrm{Si} / \mathrm{Al}$ & $\mathrm{C}$ & 2.5 & 2.6 & 2.7 \\
\hline
\end{tabular}

\begin{tabular}{ccccc}
\multicolumn{5}{c}{ TABLE-3 } \\
\multicolumn{5}{c}{ MIX PROPORTIONS OF RAW MATERIALS (wt \%) } \\
\hline Samples & Coal gangue & Fly ash & Plasticizer & Si/Al \\
\hline SA-2.7 & 51 & 34 & 15 & 2.7 \\
SA-2.6 & 42.5 & 42.5 & 15 & 2.6 \\
SA-2.5 & 34 & 51 & 15 & 2.5 \\
\hline
\end{tabular}

$$
Y=\beta_{0}+\sum_{i=1}^{k} \beta_{i} \chi_{i}+\sum_{i=1}^{k} \beta_{i i}+\sum_{i<j} \beta_{i j} \chi_{i} \chi_{j}+\varepsilon
$$

where $\mathrm{Y}$ is the predicted response value; $\beta_{0}, \beta_{\mathrm{i}}, \beta_{\mathrm{ii}}$ and $\beta_{\mathrm{ij}}$ are the constant and regression coefficients of the model; $\mathrm{x}_{\mathrm{i}}$ and $\mathrm{x}_{\mathrm{j}}$ are the variables; $\varepsilon$ is the statistical error.
Coal gangue, fly ash and plasticizer were homogenized in a blender and then aged with addition of water at room temperature for $4 \mathrm{~h}$. All cylindrical green samples were prepared by PVC pipes (size of $\Phi 25 \mathrm{~mm} \times \mathrm{L} 30 \mathrm{~mm}$ ) under a certain pressure. The samples were dried at room temperature for several days to constant weight. Then, sintered at a heating rate of $5-6^{\circ} \mathrm{C} / \mathrm{min}$ at setting maximum temperature for $30 \mathrm{~min}$ in KSL-1400X furnace. Finally, these were cooled to room temperature in the furnace.

The $V_{1}$ and $V_{2}$ represented the volumes of samples before and after sintering, respectively. The dry mass $\mathrm{M}_{1}$ of sintered products was measured before immersing in water for $24 \mathrm{~h}$ in vacuum condition and the saturated surface dry mass $\mathrm{M}_{2}$ of sintered products that wiped off the surface moisture was also measured. Compressive strength was determined by QJ212 electronic universal testing machine at $2 \mathrm{~mm} / \mathrm{s}$ load rate. The $\alpha, \rho, \omega$ and $\sigma$ were expressed by the formulae (2-4). Tests of them were carried out on 9 samples, respectively.

$$
\begin{gathered}
\alpha=\frac{V_{1}-V_{2}}{V_{1}} \times 100 \% \\
\rho=\frac{M_{1}}{V_{2}} \\
\omega=\frac{M_{2}-M_{1}}{M_{1}} \times 100 \% \\
\sigma=\frac{4 F}{\pi d^{2}}
\end{gathered}
$$

\section{RESULTS AND DISCUSSION}

The experimental results of $\alpha, \rho, \omega$ and $\sigma$ were summarized in Table-4.

TABLE-4

BOX-BEHNKEN DESIGN MATRIX AND THE RESPONSE VALUES OF SINTERED BRICKS

\begin{tabular}{cccc|cccc}
\hline \multirow{2}{*}{ Runs order } & \multicolumn{3}{c|}{ Factors and levels } & \multicolumn{4}{c}{ Response values } \\
\cline { 2 - 7 } & $\mathrm{A}\left({ }^{\circ} \mathrm{C}\right)$ & $\mathrm{B}\left(\mathrm{m}^{2} \mathrm{~kg}^{-1}\right)$ & $\mathrm{C}$ & $\alpha(\%)$ & $\rho\left(\mathrm{kg} / \mathrm{m}^{3}\right)$ & $\omega(\%)$ & $\sigma(\mathrm{MPa})$ \\
\hline 1 & 1200 & 520 & 2.6 & 17.73 & 1788 & 9.54 & 26.37 \\
2 & 1300 & 520 & 2.6 & 26.69 & 1967 & 0.32 & 63.50 \\
3 & 1200 & 680 & 2.6 & 20.94 & 1857 & 6.30 & 37.57 \\
4 & 1300 & 680 & 2.6 & 26.50 & 1988 & 0.15 & 71.74 \\
5 & 1200 & 600 & 2.5 & 19.05 & 1730 & 11.23 & 38.91 \\
6 & 1300 & 600 & 2.5 & 30.64 & 2004 & 0.16 & 58.94 \\
7 & 1200 & 600 & 2.7 & 23.23 & 1903 & 7.14 & 32.15 \\
8 & 1300 & 600 & 2.7 & 27.18 & 1965 & 0.33 & 36.44 \\
9 & 1250 & 520 & 2.5 & 23.57 & 1823 & 6.80 & 31.61 \\
10 & 1250 & 680 & 2.5 & 24.95 & 1917 & 3.42 & 41.89 \\
11 & 1250 & 520 & 2.7 & 23.03 & 1903 & 4.78 & 54.92 \\
12 & 1250 & 680 & 2.7 & 25.42 & 1979 & 0.86 & 59.53 \\
13 & 1250 & 600 & 2.6 & 27.92 & 1963 & 2.68 & 31.68 \\
14 & 1250 & 600 & 2.6 & 27.35 & 1949 & 2.36 & 33.66 \\
15 & 1250 & 600 & 2.6 & 27.90 & 1948 & 2.83 & 33.69 \\
16 & 1250 & 600 & 2.6 & 28.02 & 1947 & 2.63 & 34.07 \\
17 & 1250 & 600 & 2.6 & 27.72 & 1961 & 2.66 & 33.47 \\
\hline
\end{tabular}


Modeling: The experimentally obtained $\alpha, \rho, \omega$ and $\sigma$ of sintered brick were analyzed and fitted by Design-Expert software. The predicted response surface models of sintered brick between response values and variables were fitted using regression analysis method. The final quadratic regression equations in terms of actual factors are listed as follows: $\alpha=-3344.61+3.21 * \mathrm{~A}+0.72 * \mathrm{~B}+844.05 * \mathrm{C}-2.13 * 10^{-4} * \mathrm{~A}$ $* \mathrm{~B}-0.38 * \mathrm{~A} * \mathrm{C}+3.2 * 10^{-2} * \mathrm{~B} * \mathrm{C}-8 * 10^{-4} * \mathrm{~A}^{2}-4.4 * 10^{-4} *$ $\mathrm{B}^{2}-73.98 * \mathrm{C}^{2}$

$\rho=-744551.58+60.28 * \mathrm{~A}+10.18 * \mathrm{~B}+26308.5 * \mathrm{C}-3 * 10^{-3}$

$* \mathrm{~A} * \mathrm{~B}-10.6 * \mathrm{~A} * \mathrm{C}-0.56 * \mathrm{~B} * \mathrm{C}-1.12 * 10^{-2} * \mathrm{~A}^{2}-3.8 * 10^{-3} *$

$\mathrm{C}^{2}-2380 * \mathrm{C}^{2}$

$\omega=2325.72-1.85 * \mathrm{~A}-0.28 * \mathrm{~B}-779.08 * \mathrm{C}+2 * 10^{-4} * \mathrm{~A} * \mathrm{~B}+$ $0.21 * \mathrm{~A} * \mathrm{C}-1.7 * 10^{-2} * \mathrm{~B} * \mathrm{C}+4 * 10^{-3} * \mathrm{~A}^{2}+5 * 10^{-6} * \mathrm{~B}^{2}$ $+98.53 * C^{2}$

$\sigma=2631.14 * \mathrm{~A}-1.31 * \mathrm{~B}-322.34 * \mathrm{C}-2 * 10^{-4} * \mathrm{~A} * \mathrm{~B}-0.79$

$* \mathrm{~A} * \mathrm{C}-0.18 * \mathrm{~B} * \mathrm{C}+2 * 10^{-3} * \mathrm{~A}^{2}+1.7 * 10^{-3} * \mathrm{~B}^{2}+274.43$ $* \mathrm{C}^{2}$

Significance checking: Generally, $p$-values are used to verify the significance of fitting models and each coefficient. Thus terms in ANOVA with $p$-valued $\leq 0.05$ are regarded as significance, indicating that the fitness of models is good. However, $p$-value $>0.05$ indicated that model terms are insignificant, thus the model needs to further revised. The analysis of variance (ANOVA) of the predicted response surface quadratic models are summarized in Table-5. According to the ANOVA in Table-5, the predicted response surface quadratic models of $\alpha, \rho$ and $\omega$ with $p$-value $<0.0001$ are significant and the corresponding correlation coefficients $\left(\mathrm{R}^{2}\right.$ value) are 0.9971 , 0.9878 and 0.9843 , respectively, indicating that the fitnesses of the model are excellent, it can be used to analyze and to predict the $\alpha, \rho$ and $\omega$ of sintered brick. However, slightly poor fitness was obtained for $\sigma$. This because that quadratic model with $p$-value $>0.05$ for $\sigma$ is insignificant. In addition, its correlation coefficient $\left(\mathrm{R}^{2}\right.$ value $)$ is 0.7002 .

In order to predict the response better, the single and interaction effect between factor and factor should be known. The results indicated that linear effect of $\mathrm{A}$ and $\mathrm{B}$, interaction effects of $\mathrm{AB}$ and $\mathrm{AC}$, quadratic effect of $\mathrm{A}^{2}, \mathrm{~B}^{2}$ and $\mathrm{C}^{2}$ were significant for $\alpha$. However, linear effect of $C$ and interaction between $\mathrm{B}$ and $\mathrm{C}$ were insignificant in this case. The linear effects of $\mathrm{A}, \mathrm{B}$ and $\mathrm{C}$ and quadratic effects of $\mathrm{A}^{2}, \mathrm{~B}^{2}$ and $\mathrm{C}^{2}$ and interaction effect between $\mathrm{A}$ and $\mathrm{C}$ on $\rho$ were significant. However, the interaction terms $\mathrm{AB}$ and $\mathrm{BC}$ did not produce a significant effect in this case. In this case A, B, C, AB, AC, $\mathrm{A}^{2}$ and $C^{2}$ were significant model terms for $\omega$. Whereas the quadratic term $\mathrm{B}^{2}$ and interaction effect between $\mathrm{B}$ and $\mathrm{C}$ were insignificant for $\omega$. Only the linear terms of A produced a significant effect on compressive strength $\sigma$. However, other terms were insignificant in this case.

Interaction effect between temperature and specific surface area on properties of sintered bricks: The 3D response surface plots of the interaction effect between temperature and specific surface area on properties of sintered brick were shown in Fig. 1. Fig. 1(a) illustrated the 3D plots of the interaction effect between temperature and specific surface area on $\alpha$. It had an increasing trend with increasing temperature and increased with the increase of specific surface area to $600 \mathrm{~m}^{2}$ $\mathrm{kg}^{-1}$, but decreased with further increase. The $\rho$ increased by increasing temperature and specific surface area, which were observed in Fig. 1(b). In contrast, an almost opposite trend was observed for $\omega$, the $\omega$ decreased with increase in temperature and specific surface area (Fig. 1(c)). In addition, temperature had a greater significance on $\omega$ than specific surface area on it. Temperature had a great influence on $\sigma$, moreover, the $\sigma$ increased with the increasing temperature, which could be seen in Fig. 1(d).

Based on the ANOVA of quadratic models, the interaction effect between temperature and specific surface area on $\alpha$ and $\rho$ of sintered brick were highly significant, as well as temperature had a great significance on $\omega$ and $\sigma$. Considering energy consumption and overall properties of sintered brick, the sintered brick with excellent properties was obtained at temperature of $1250{ }^{\circ} \mathrm{C}$ and specific surface area around 600 $\mathrm{m}^{2} \mathrm{~kg}^{-1}$.

Interaction effect between temperature and $\mathrm{Si} / \mathrm{Al}$ on properties of sintered bricks: Fig. 2 showed the 3D response surface plots of the interaction effect between temperature and $\mathrm{Si} / \mathrm{Al}$ on properties of sintered brick. The interaction effect between temperature and $\mathrm{Si} / \mathrm{Al}$ on $\alpha$ was seen in Fig. 2(a). When the $\mathrm{Si} / \mathrm{Al}<2.6$, the $\alpha$ increased with the increasing temperature. The $\mathrm{Si} / \mathrm{Al}>2.6$, the $\alpha$ increased with the increasing temperature and reached a maximum value followed by a decrease with further increase in the temperature. However,

TABLE-5

ANALYSIS OF VARIANCE (ANOVA) FOR THE FITTED QUADRATIC MODELS OF PROPERTIES OF SINTERING BRICKS

\begin{tabular}{|c|c|c|c|c|c|c|c|c|}
\hline \multirow{2}{*}{ Source } & \multicolumn{2}{|c|}{$\alpha$} & \multicolumn{2}{|c|}{$\rho$} & \multicolumn{2}{|c|}{$\omega$} & \multicolumn{2}{|c|}{$\sigma$} \\
\hline & F-Value & $p$-Value & F-Value & $p$-Value & F-Value & $p$-Value & F-Value & $p$-Value \\
\hline Model & 269.62 & $<0.0001$ & 62.89 & $<0.0001$ & 48.88 & $<0.0001$ & 1.82 & 0.2218 \\
\hline A-A & 1415.79 & $<0.0001$ & 322.66 & $<0.0001$ & 339.46 & $<0.0001$ & 8.91 & 0.0204 \\
\hline B-B & 72.24 & $<0.0001$ & 52.27 & 0.0002 & 35.22 & 0.0006 & 1.15 & 0.3195 \\
\hline $\mathrm{C}-\mathrm{C}$ & 0.66 & 0.4427 & 58.9 & 0.0001 & 22.18 & 0.0022 & 0.13 & 0.726 \\
\hline $\mathrm{AB}$ & 36.22 & 0.0005 & 3.56 & 0.101 & 5.79 & 0.0471 & 0.017 & 0.8997 \\
\hline $\mathrm{AC}$ & 182.91 & $<0.0001$ & 69.5 & $<0.0001$ & 11.14 & 0.0124 & 0.48 & 0.5096 \\
\hline $\mathrm{BC}$ & 3.2 & 0.1169 & 0.5 & 0.5019 & 0.18 & 0.6849 & 0.063 & 0.8096 \\
\hline $\mathrm{A}^{2}$ & 214.77 & $<0.0001$ & 22.36 & 0.0021 & 12.46 & 0.0096 & 1.01 & 0.3481 \\
\hline $\mathrm{B}^{2}$ & 413.7 & $<0.0001$ & 15.38 & 0.0057 & 1.25 & 0.3003 & 3.92 & 0.0882 \\
\hline $\mathrm{C}^{2}$ & 28.88 & 0.001 & 14.75 & 0.0064 & 10.04 & 0.0157 & 0.25 & 0.6343 \\
\hline Lack of fit & 1.33 & 0.3833 & 4.97 & 0.0776 & 31.34 & 0.0631 & 338.22 & $<0.0001$ \\
\hline $\mathrm{R}^{2}$ & \multicolumn{2}{|c|}{0.9971} & \multicolumn{2}{|c|}{0.9878} & \multicolumn{2}{|c|}{0.9843} & \multicolumn{2}{|c|}{0.7002} \\
\hline
\end{tabular}

Notes: Significance at $p \leq 0.05$; insignificance at $p>0.05$. 


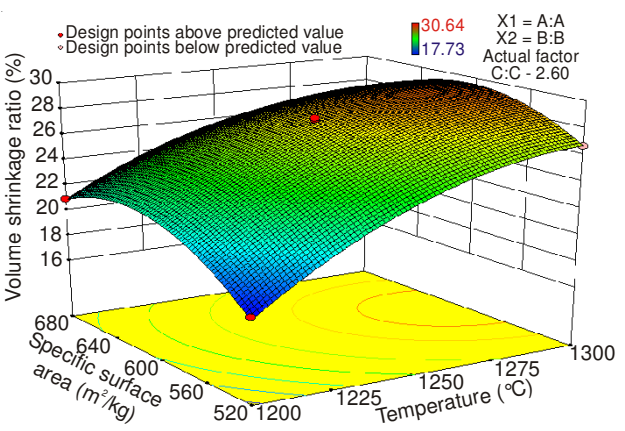

(a) 3D plot of the interaction between temperature and specific surface area on volume shrinkage ratio

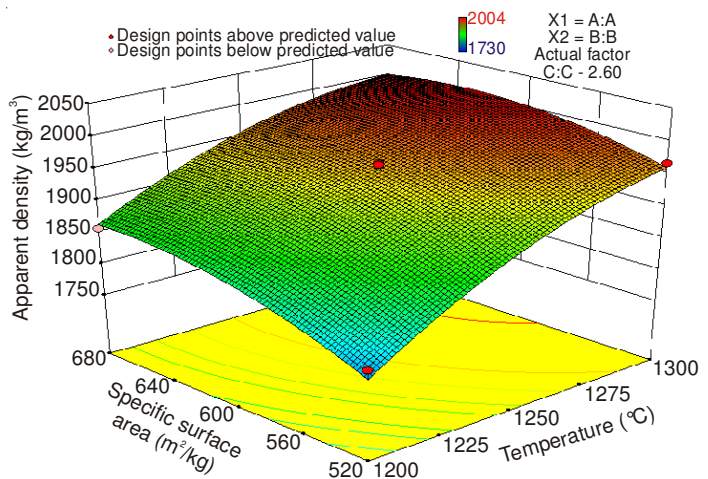

(b) $3 \mathrm{D}$ plot of the interaction between temperature and specific surface area on apparent density

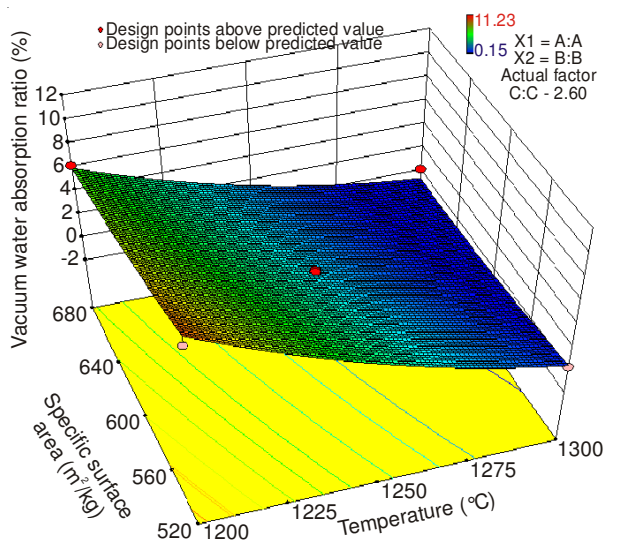

(c) 3D plot of the interaction between temperature and specific surface area on vacuum water absorption

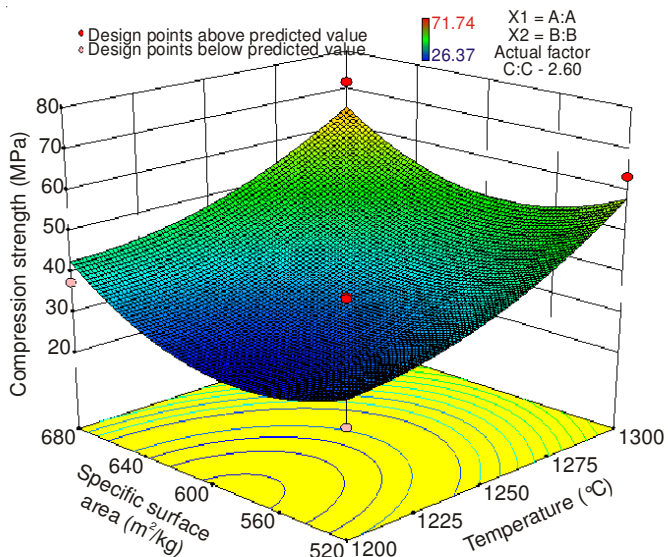

(d) 3D plot of the interaction between temperature and specific surface area on compressive strength

Fig. 1. Interaction effect between temperature and specific surface area on properties of sintered brick

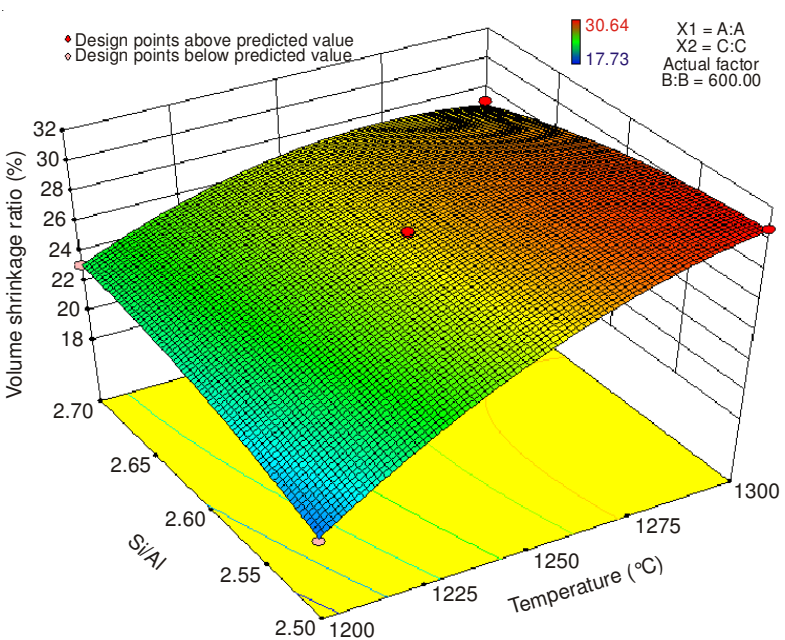

(a) $3 \mathrm{D}$ plot of the interaction between temperature and $\mathrm{Si} / \mathrm{Al}$ on volume shrinkage ratio

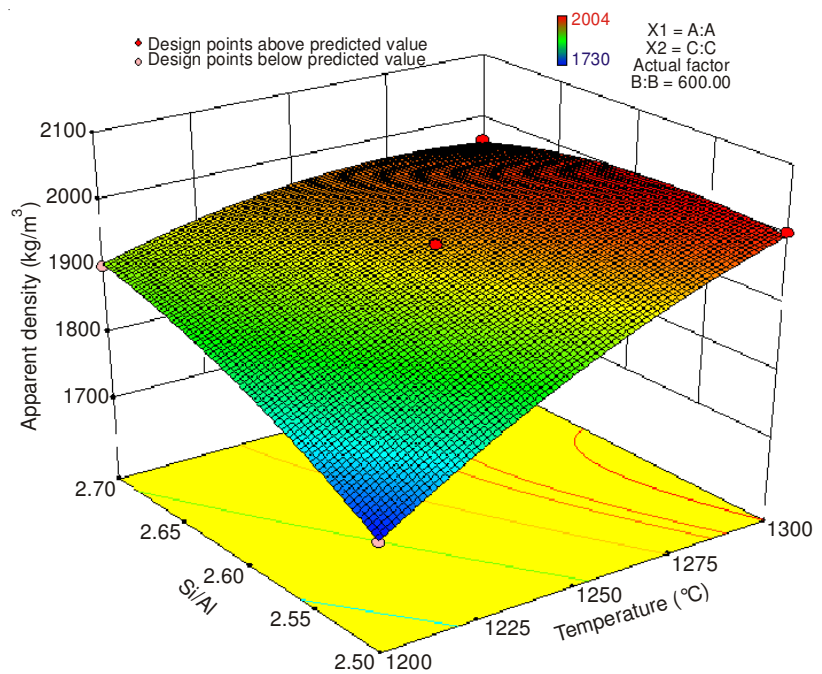

(b)

$3 \mathrm{D}$ plot of the interaction between temperature and $\mathrm{Si} / \mathrm{Al}$ on apparent density

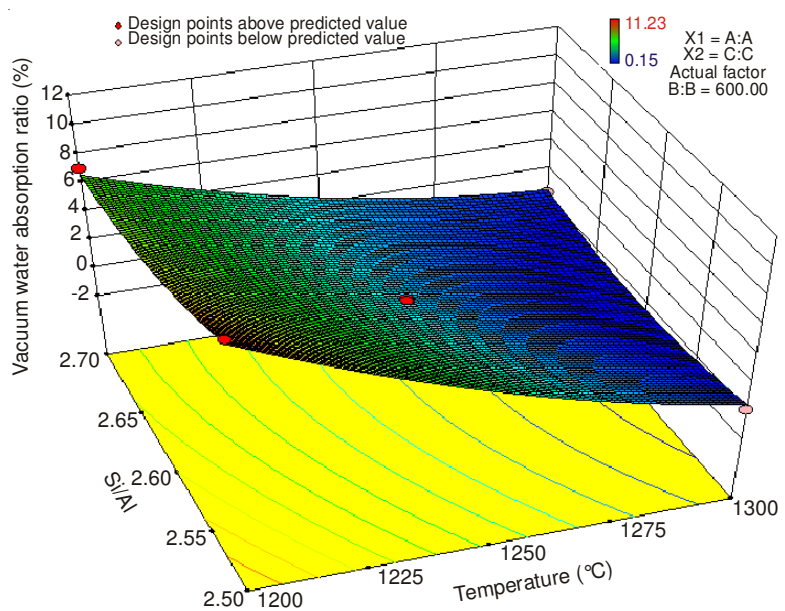

(c) $3 \mathrm{D}$ plot of the interaction between temperature and $\mathrm{Si} / \mathrm{Al}$ on vacuum water absorption

Fig. 2. Influence of the interaction between temperature and Si/Al on properties of sintered brick

when temperature less than $1250^{\circ} \mathrm{C}$ the $\alpha$ had an increasing trend with the increase in $\mathrm{Si} / \mathrm{Al}$. When the $\mathrm{Si} / \mathrm{Al}>2.65$ and temperature greater than $1275^{\circ} \mathrm{C}$, the $\alpha$ decreased by increasing 
temperature and $\mathrm{Si} / \mathrm{Al}$. And a similar trend was observed for apparent density $\rho$ as shown in Fig. 2(b). Fig. 2(c) illustrated the interaction effect between temperature and $\mathrm{Si} / \mathrm{Al}$ on $\omega$. The $\omega$ decreased with increasing temperature and Si/Al. Considering energy consumption and overall properties of sintered brick, the sintered brick with excellent properties was obtained at temperature of $1250{ }^{\circ} \mathrm{C}$ and $\mathrm{Si} / \mathrm{Al}$ of around 2.6.

Parameter optimization: The main objective of our investigation had been to obtain the sintered brick with a smaller volume shrinkage and higher compressive strength. Considering the properties of sintered brick and energy consumption, the technical parameters for preparation of excellent sintered brick were determined by RSM, which were of 1225 $1250{ }^{\circ} \mathrm{C}$ in sintering temperature, of around $600-640 \mathrm{~m}^{2} \mathrm{~kg}^{-1}$ in specific surface area of coal gangue and ratio of $\mathrm{Si} / \mathrm{Al}=$ 2.5-2.6.

\section{Conclusion}

The quadratic regression models were significant for volume shrinkage ratio $(\alpha)$, apparent density $(\rho)$ and vacuum water absorption $(\omega)$ of sintered brick and could allow to analyze and to predict the effect of the three parameters on the properties of sintered brick. Furthermore, the interaction effect of temperature-specific surface area of coal gangue and temperature$\mathrm{Si} / \mathrm{Al}$ were also significant for $\alpha, \rho$ and $\omega$ of sintered brick. The technical parameters for preparation of excellent sintered brick were determined by RSM, which were of $1225-1250^{\circ} \mathrm{C}$ in sintering temperature, of around $600-640 \mathrm{~m}^{2} \mathrm{~kg}^{-1}$ in specific surface area of coal gangue and ratio of $\mathrm{Si} / \mathrm{Al}=2.5-2.6$.

\section{ACKNOWLEDGEMENTS}

This research is financially supported by the National Natural Science Foundation of China (51308004), Anhui Science and Technology Research Project(1301042127), Anhui Provincial Natural Science Foundation (1308085QE88 and 1208085ME82) and Nature Science Foundation of Education Agency of Anhui Province (KJ2012A052).

\section{REFERENCES}

1. L.L. Xu, W. Guo, T. Wang and N.R. Yang, Constr. Build. Mater, 19, 243 (2005).

2. L.Y. Zhang, Construct. Build. Mater., 47, 643 (2013).

3. W.J. Song, H.L. Xu, H. Guo, H.X. Lu, W.B. Cao, R. Zhang, Y.N. Wu and Z.H. Zhang, China Ceramics, 47, 8 (2011).

4. K.-Y. Chiang, K.-L. Chien and S.-J. Hwang, J. Hazard. Mater., 159, 499 (2008).

5. J.G. Song and B.L. Wu, Mater. Sci. Technol., 15, 569 (2007).

6. Q.J. Ding, X.L. Huang, H. Sun and K. Yang, Adv. Mater. Res., 168170, 1625 (2010).

7. $\quad$ N.U. Kockal and T. Ozturan, Mater. Des., 32, 3586 (2011).

8. S. Mannan, A. Fakhru'l-Razi and M.Z. Alam, J. Environ. Sci. (China), 19, 23 (2007). 